\title{
A economia política e os impactos macroeconômicos da elevação da carga tributária brasileira na última década: um contexto para o PAC
}

\author{
Clándio H. dos Santos \\ Manoel Carlos de Castro Pires*
}

\section{Introdução}

Em primeiro de março de 2007, o Instituto Brasileiro de Planejamento Tributário (IBPT) aferiu uma estimativa para a carga tributária de 38,8\% do PIB para o ano de 2006. O último dado oficial de 2003, apresentado pelo IBGE, indica que a mesma se situava em $34 \%$ do PIB, ou seja, em três anos assistimos a um aumento na carga tributária de 4,8 pontos percentuais do PIB. Se levarmos em conta que essa variável foi, segundo o próprio IBGE, equivalente a 28,4\% do PIB em 1995, chegamos a uma conclusão ainda mais impressionante, isto é a de que em onze anos a carga tributária brasileira aumentou 10,4 p.p., uma média próxima de $1 \%$ do PIB por ano.

Dados os fortes efeitos redistributivos associados a uma elevação dessa natureza que no Brasil só encontra paralelo histórico no período imediatamente posterior ao golpe de 1964 e a implantação da ditadura militar - não é particularmente surpreendente que a mesma esteja no centro do debate macroeconômico brasileiro atual. Com efeito, não são poucos os economistas brasileiros que, como Velloso (2006, p.1), acreditam que:

"o Brasil não consegue crescer a taxas elevadas porque não resolveu o desequilíbrio crônico de suas contas públicas. Esse desequilibrio joga todo o ônus do controle da inflação sobre a politica monetária, que precisa lançar mão de juros estratosféricos para manter a inflação sob controle,enquanto o déficit fiscal continua jogando lenha na fogueira da demanda agregada, que pressiona os preços. [É fato que], desde 1999 o Governo Federal tem gerado seguidos e crescentes superávits primários. Mas (...) [essa] geração de superávits primários tem sido baseada em aumentos de receita e corte do investimento público, e não em corte de gastos correntes, que continuam a crescer em ritmo elevado. Essa estratégia tem dois problemas. Em primeiro lugar, deprime o crescimento econômico de longo praz̧. O aumento da carga tributária onera os investimentos [privados], enquanto a redução dos investimentos públicos leva à deterioração da infra-estrutura necessária ao crescimento (transportes e energia, principalmente). Em segundo lugar, a estratégia tem vida curta, tanto porque não se pode aumentar indefinidamente a carga tributária (até tributar 100\% da renda nacional), quanto porque não se pode reprimir o investimento público para o resto da vida: as estradas se transformam em crateras, a falta de energia elétrica leva a sucessivos apagões."

*Economista do IPEA. Doutorando em Economia pela Unb. Endereço eletrônico: manoel.pires@ipea.gov.br 
Também não são poucos os economistas brasileiros que, ao analisarem as significativas melhorias observadas nas últimas duas décadas tanto na extensão quanto na qualidade da oferta de bens públicos disponíveis aos cidadãos brasileiros, acabam por concluir, tal como Coutinho (2006, p.9-10), que:

"A pressão incisiva de diversos setores organizados da sociedade brasileira na defesa da extensão de direitos à massa da população, a compreensão de parte majoritária do Congresso Nacional da importância de assegurar prioridade orçamentária a certas áreas da política social e a disposição governamental em executar determinados programas de ação, fez que os indicadores sociais tivessem o comportamento observado nos últimos anos, expressando melhorias concretas em importantes dimensões da vida social."

A principal motivação desse artigo é nossa insatisfação com o fato de que poucos macroeconomistas parecem conhecer e/ou se preocupar com o segundo consenso (repetido em dez entre dez seminários com economistas especializados em "políticas sociais"), tomando como dada a necessidade de se diminuir o tamanho do estado brasileiro e praticamente exaurindo a lista de adjetivos pejorativos existentes na língua portuguesa ao descrever os níveis de eficiência do mesmo (geralmente com base em evidências anedóticas ${ }^{1}$ ). Ainda que reconheçamos prontamente que o estado brasileiro pode e deve se tornar muito mais eficiente do que é, notamos que dificilmente os aumentos de produtividade possíveis teriam o poder de tornar o gasto brasileiro per capita em bens públicos compatíveis com as justas demandas populares (e.g. serviços públicos de saúde, educação, saneamento, estradas, segurança, controle de desmatamentos, etc) apresentadas diariamente nos meios de comunicação.

Parece-nos, assim, que o "consenso" entre macroeconomistas sobre a necessidade de "melhorar a qualidade do ajuste fiscal" (isto é, manter o elevado nível do superávit primário atual com o corte simultâneo de gastos e da carga tributária) é por demais insensível às necessidades presentes dos brasileiros mais dependentes de serviços públicos ${ }^{2}$. Ou, dito de outro modo, parece-nos que os macroeconomistas em questão trabalham (implicitamente)

\footnotetext{
${ }^{1}$ Dentre as louváveis exceções a essa regra, destacamos os estudos recentes do IPEA, no âmbito da Coordenação de Finanças Públicas (em Brasília) e da Diretoria de Estudos Macroeconômicos (no Rio da Janeiro), aplicando as metodologia DEA (do inglês "Data Envelopment Analysis") e modelos de "fronteira estocástica" para mensurar as ineficiências de setores do estado brasileiro. Apesar dessa literatura ser ainda incipiente - e das inevitáveis imperfeições dos referidos métodos - os resultados já obtidos parecem indicar que há, de fato, espaço considerável para aumentos na eficiência do estado brasileiro.

2 Nesse contexto, notamos que a disseminação do uso de modelos baseados na hipótese de "agente representativo" entre macroeconomistas ortodoxos, infelizmente, não tem contribuído para aguçar a sensibilidade dos mesmos em relação a problemas (de curto e longo prazos) relacionados a má distribuição de renda - ainda que microeconomistas ortodoxos (além, obviamente, de macroeconomistas heterodoxos) não se cansem de apontar a importância dos mesmos (e a infelicidade, em vários outros sentidos, da hipótese de agente representativo").
} 
com uma "função de bem-estar social" em que a preocupação com o crescimento econômico tem um peso maior que a redução da desigualdade e/ou com uma "função macroeconômica de produção" que despreza os impactos negativos da má distribuição de renda (ou, mais geralmente, do acesso a bens) sobre a "produtividade total dos fatores".

Por outro lado, nos parece também que a visão dos "economistas sociais" é freqüentemente viesada na direção oposta, isto é, tende a colocar um peso muito grande na questão distributiva e a minimizar, ou mesmo ignorar, os impactos dessa última sobre o crescimento da economia. Feliz ou infelizmente, entretanto, esses economistas têm tido pouca influência na definição da política macroeconômica brasileira.

O presente texto visa contribuir de três maneiras para o aprofundamento do debate sobre a definição da política macroeconômica no Brasil em geral - e dos termos do trade-off entre tributação/distribuição e crescimento à disposição da sociedade brasileira em particular. Em primeiro lugar, nas seções 2 e 3, apresentamos brevemente a metodologia utilizada e os resultados reportados em trabalhos recentes de nossa autoria, realizados no âmbito da Coordenação de Finanças Públicas do IPEA, que parecem indicar que elevações de 1\% na carga tributária bruta medida em relação ao PIB tendem no longo prazo a gerar diminuições de 1\% no investimento privado medido a preços constantes de agosto de 1994. Em segundo lugar, na seção 4, descrevemos e analisamos brevemente o processo de elevação da carga tributária brasileira no período 1995-2005. Em terceiro lugar, na seção 5, analisamos as opções estratégicas implícitas no PAC à luz dos resultados e considerações expostos nas seções anteriores. A sexta e ultima seção desse artigo apresenta notas à guisa de conclusão.

\section{Novas estimativas trimestrais da carga tributária bruta e do investimento} privado

O IBGE apresenta nas Contas Econômicas Integradas (CEI), dados oficiais sobre a carga tributária bruta brasileira. Tais dados são problemáticos por dois motivos básicos. O primeiro problema é que os últimos dados oficiais do IBGE são de 2003 (ainda que estimativas não oficiais para a carga tributária bruta agregada em 2004 e 2005 tenham sido produzidas pela Secretaria da Receita Federal). O segundo e mais importante problema é que os dados do IBGE (e da SRF) são anuais, o que dificulta sobremaneira estudos empíricos sobre o tema (notadamente se levarmos em conta as várias mudanças estruturais por quais passou a economia brasileira desde a segunda metade do século XX). Para piorar as coisas, os dados oficiais sobre o investimento privado (incluindo nessa definição os investimentos de 
empresas estatais) também são anuais e também param em 2003 - apenas os dados da "formação bruta de capital fixo" agregada da economia (que incluem os investimentos do setor público) estão disponíveis nas Contas Nacionais Trimestrais.

Felizmente, três desenvolvimentos recentes contribuíram para atenuar parcialmente o problema da escassez de dados de alta freqüência sobre o investimento privado e a carga tributária no Brasil. Primeiramente, a Secretaria do Tesouro Nacional (STN) tem feito um louvável esforço no sentido de ampliar a base de dados disponíveis sobre a execução orçamentária-financeira de estados e municípios (no contexto da implementação dos mecanismos de controle previstos na Lei de Responsabilidade Fiscal), compilando inclusive dados de alta freqüência sobre os "gastos de investimento" desses entes da federação. Em segundo lugar, o excelente estudo de Gobetti (2006) iluminou consideravelmente a relação entre os dados contábeis das "despesas de investimento" da execução orçamentária-financeira da união/estados/municípios/estatais e os dados sobre a "formação bruta de capital fixo" (da administração pública) das contas nacionais - além de apresentar estimativas confiáveis dessa última variável (usando a metodologia do IBGE) para os anos de 2004 e 2005 e uma lista detalhada tanto dos problemas associados à mesma quanto dos possíveis modos de atenuálos. Finalmente, e novamente em virtude da saudável disposição da STN de tornar transparentes os dados relativos a execução orçamentária-financeira da união, é possível construir estimativas bastante razoáveis da carga tributária brasileira bruta trimestral (tal como medida pelo IBGE - ver Dos Santos e Costa, 2007).

A construção de uma série trimestral da FBCF privada foi mais complicada. Uma vez obtidas as referidas séries mensais da Secretaria do Tesouro Nacional (STN) sobre as "despesas de investimento" dos governos federal, estaduais e municipais e das empresas estatais federais - a partir de contato pessoal com a referida instituição - Dos Santos e Pires (2007) tiveram que converter esses dados (contábeis) para o conceito economicamente relevante de "formação bruta de capital fixo" - seguindo de perto a metodologia de Gobetti (2006). Uma vez calculadas as estimativas da FBCF pública trimestral (com e sem o investimento das estatais), Dos Santos e Pires (2007) puderam então obter estimativas da FBCF privada trimestral subtraindo a FBCF pública estimada da FBCF total da economia reportada nas contas nacionais trimestrais do IBGE. 


\section{Qual a elasticidade-carga tributária do investimento privado brasileiro?}

Além de apresentarem as supracitadas estimativas trimestrais da FBCF privada brasileira, Dos Santos e Pires (2007) estimam ainda a sensibilidade dessa última variável a variações na carga tributária bruta agregada (tal como estimada por Dos Santos e Costa, 2007). Como de costume em estimativas da "função investimento" (privado), as variáveis explicativas utilizadas por Dos Santos e Pires foram o PIB (para captar o "efeito acelerador"), o preço relativo do capital ( $\not k$, como medida do custo de oportunidade do investimento), a carga tributária $(c t)$ e o investimento público ( $p u b$, para captar efeitos de complementaridade e de substitutibilidade entre as FBCFs privada e governamental). A estimativa da função de investimento (i.e. o "vetor de cointegração") obtida (o) por Dos Santos e Pires para a equação do investimento privado (para o período 1995:1-2006:3 e assumindo a inexistência de quebras estruturais) foi ${ }^{3}$ :

$$
\text { Priv }=-1,87+1,92 p i b-0,81 p k-1,09 c t-0,14 p u b
$$

Por outro lado, as funções investimento obtidas assumindo uma quebra estrutural no (nível e na inclinação da relação de longo prazo entre as variáveis em questão) no quarto trimestre de 2001 foram $^{4}$ :

$$
\begin{aligned}
& \text { Priv }=-3,62+1,78 p i b-0,33 p k-0,61 c t-0,1 \text { pub } \\
& \text { Priv }=-6,81+2,05 p i b+0,06 p k-1,41 c t+0,04 p u b
\end{aligned}
$$

Apesar do problema da redução dos graus de liberdade das estimativas obtidas assumindo-se a hipótese de quebra estrutural, os resultados obtidos nesse caso são quase todos qualitativamente semelhantes às estimativas sem quebra estrutural (a exceção foi o coeficiente associado ao preço do capital). Essencialmente os mesmos resultados foram encontrados ainda em outras estimativas (não reportadas aqui), que controlam pela possibilidade de várias relações de cointegração (utilizando o procedimento de Johansen, 1991

\footnotetext{
3 O processo de estimação nesse caso seguiu a metodologia proposta por Engle e Granger (1987). Para a execução do procedimento de cointegração tivemos que avaliar o grau de integração das séries. Ao aplicar o teste de raiz unitária $\mathrm{ADF}$ e os testes de raiz unitária que contemplam a presença de quebra estrutural (Perron, Zivot e Andrews e Franses e Haldrup) apresentamos evidências de que todas as séries são integradas de ordem 1. A peculiaridade ficou por conta dos investimentos públicos que são estacionários quando as empresas estatais não são contabilizadas ou possuem raiz unitária quando as empresas estatais são incluídas. Assim, para aplicarmos a análise de cointegração os investimentos públicos incluem as empresas estatais (federais).

${ }^{4} \mathrm{O}$ processo de estimação nesse caso seguiu a metodologia proposta por Gregory e Hansen (1996). A existência de quebras estruturais na carga tributária brasileira na vizinhança do período em questão é bem conhecida na literatura (e.g. Giambiagi, 2006).
} 
e assumindo a ausência de tendências determinísticas nessas relações de cointegração). Dada a incomum robustez dos resultados que obtiveram, Dos Santos e Pires (2007) se permitiram concluir que o investimento privado brasileiro aparenta possuir elevada elasticidade-produto (próxima de 2) e elasticidade-carga tributária (em torno de menos 1).

\section{Elevar quais impostos e por quais motivos? Uma análise menos agregada}

Mas o que motivou a elevação da carga tributária brasileira de 28,4\% para 38,8\% do PIB no período 1995-2006? E como se deu essa elevação?

Começando pela primeira questão, e correndo o risco de uma simplificação excessiva, parece-nos possível dizer que conjuntos de fatores foram responsáveis pelo aumento da carga tributária nos últimos onze anos. O primeiro conjunto de fatores diz respeito ao significativo aumento das transferências do governo ao setor privado registrado no período em questão. Uma vez que essas transferências são bastante heterogêneas (compreendendo os gastos com a previdência social, a política social e o pagamento de juros sobre a dívida pública), alguns comentários são necessários aqui.

Primeiramente, notamos a influência da universalização de direitos promovida pela constituição de 1988 no crescimento de algumas despesas primárias, sobretudo, as relativas à previdência social. Obviamente, o aumento da carga tributária que foi efetuado para cobrir os gastos com o pagamento desses benefícios adicionais se deveu única e exclusivamente à necessidade de cumprir o que foi estabelecido pela constituição de 1988 sem aumentar concomitantemente o déficit público. Em segundo lugar, notamos que a mudança de poder em 2002 que colocou o PT na presidência da república refletiu o desejo por parte da maioria da sociedade brasileira de uma política social de transferências ativas aos mais pobres, o que não seria possível sem o aumento da carga tributária. $O$ terceiro comentário é que o pagamento de juros é comandado, em sua maior parte, pela política monetária e não pela política fiscal, razão pela qual o aumento da carga tributária com essa finalidade apenas valida decisões do Banco Central do Brasil que tem se comportado de forma independente no período.

O segundo conjunto de fatores tem a ver com a elevação do superávit primário que foi necessária para manter a trajetória de sustentabilidade/queda da dívida pública (que por sua vez sofreu dois fortíssimos impactos negativos com as desvalorizações cambiais de 1999 e 2002). Nunca é demais lembrar que o Brasil saiu de um déficit primário de 5,64\% do PIB em 1994 para um superávit primário de 4,31\% do PIB em 2006 (uma virada da ordem de 10\% do 
PIB, portanto). Em 2007, com o lançamento do PAC, está previsto um corte nesse superávit de até $0,5 \%$ do PIB na meta anterior que era de 4,25\% do PIB. Naturalmente, a redução da dívida pública nos últimos três anos figura entre os fatores mais importantes que viabilizaram essa queda. Esta é, talvez, a primeira brecha, em dez anos, para uma redução não obviamente inflacionária da carga tributária brasileira.

Passando agora a segunda questão, notamos que os aumentos recentes da carga tributária brasileira alteraram a composição dessa última variável de modo a fornecer algumas idéias acerca dos possíveis mecanismos de transmissão por trás do resultado agregado exposto na seção 3 acima.

A tabela 1 apresenta a distribuição da carga tributária brasileira no período 19952005. Notamos que os impostos sobre produção (IP) permaneceram constantes no período. No entanto, a categoria "outros impostos ligados a produção" (OILP) cresceu 3\% do PIB em dez anos, enquanto a categoria "contribuições previdenciárias" (CP) cresceu 2\% do PIB e, por último, a categoria impostos sobre a renda e propriedade (IRP) subiu quase 4\% do PIB (sendo, portanto, a que mais cresceu).

Ainda que do ponto de vista da eficiência tributária ceteris paribus seja melhor tributar renda e patrimônio (o item que mais aumentou na tabela acima), notamos que, mesmo se bem desenhados, esses impostos reduzem o lucro líquido associado a atividades produtivas e, portanto, reduzem os incentivos ao investimento. Infelizmente, o aumento da parcela dos IRPs na carga tributaria brasileira se deveu em grande medida à introdução da CPMF, um imposto particularmente ineficiente. Por outro lado, também os aumentos nas contribuições previdenciárias (incluindo as de trabalhadores autônomos e as contribuições patronais) e nos “outros impostos sobre a produção" (notadamente COFINS, PASEP e CIDE5) contribuíram para aumentar de forma significativa a carga sobre as atividades econômicas, notadamente os custos dos fatores de produção trabalho e capital. Em suma, talvez pior - em termos de impacto sobre o investimento - que o aumento da carga tributária em si, tenha sido a forma pela qual se deu esse aumento.

\footnotetext{
${ }^{5}$ Que, apesar da nomenclatura enganosa, são essencialmente impostos sobre produtos, e que, por isso, passarão a ser contabilizados como tal nas novas contas nacionais "referência 2000" do IBGE.
} 
Tabela 1. Distribuição e evolução da carga tributária no Brasil (\% PIB)

\begin{tabular}{cccccc}
\hline Ano & IP & OILP & CP & IRP & TOTAL \\
\hline 1995 & 11.51 & 4.60 & 6.43 & 5.90 & 28.44 \\
1996 & 10.77 & 4.46 & 7.56 & 5.84 & 28.63 \\
1997 & 10.37 & 4.25 & 7.42 & 6.54 & 28.58 \\
1998 & 10.22 & 4.13 & 7.74 & 7.25 & 29.33 \\
1999 & 10.62 & 5.37 & 7.80 & 7.29 & 31.07 \\
2000 & 10.84 & 5.68 & 7.55 & 7.55 & 31.61 \\
2001 & 11.26 & 6.14 & 7.83 & 8.17 & 33.40 \\
2002 & 10.91 & 6.70 & 7.98 & 9.29 & 34.88 \\
2003 & 10.32 & 6.84 & 7.83 & 9.03 & 34.01 \\
2004 & 10.48 & 7.63 & 8.21 & 8.88 & 35.20 \\
2005 & 10.79 & 7.66 & 8.62 & 9.79 & 36.86 \\
\hline Fonte: dos Santos e Costa (2007) & & &
\end{tabular}

Finalmente, cumpre perguntar: se a carga tributária no Brasil é um problema tão grande, por que, então, a discussão em torno da sua reforma e redução não avança?

Em primeiro lugar, não percebemos uma comoção da sociedade brasileira a respeito desse tema. De certa forma, isso ficou claro na campanha eleitoral de 2006 quando a população optou pela continuidade do governo. Em certo sentido, isso não é de se estranhar na medida em que nenhum cidadão consegue ter estimativas do quanto paga de impostos na compra dos produtos mais simples. Nos países mais avançados, em matéria tributária, o imposto é pago separadamente do produto de forma que o cidadão tem consciência plena da cunha fiscal imposta pelo Estado em cada transação que faz.

Em segundo lugar está a discussão do federalismo fiscal brasileiro. A autonomia tributária permitida pela legislação vigente estimula a guerra fiscal. Além disso, a cobrança do ICMS na origem e não no destino pune o produtor e torna as exportações menos competitivas. A questão da cobrança do ICMS é o principal entrave na reforma tributária, pois estados importantes da federação brasileira perderão receitas. As propostas atuais trilham o caminho de um fundo de compensações a ser gerido pela União e poderão significar aumentos ainda maiores da carga tributária. 
5. O Programa de Aceleração do Crescimento (PAC) e as difíceis escolhas à disposição da sociedade brasileira

Visto em uma perspectiva histórica, o PAC é único em vários aspectos. Trata-se, em nossa opinião, do primeiro programa governamental de desenvolvimento da história do país a se caracterizar simultaneamente por (i) intervencionismo estatal; (ii) ausência de impacto inflacionário evidente; (iii) "vontade política" por parte dos proponentes; e (iv) discussão democrática, no âmbito do Congresso Nacional, prévia à sua aprovação e execução. Visto pela ótica liberal e "curto-prazista" pela qual a maioria dos analistas macroeconômicos se acostumou a analisar as políticas macroeconômicas brasileiras, o PAC possui ainda a especificidade de ser um plano econômico que - mesmo anunciando ex-ante e com todas as letras que o superávit primário do governo será reduzido para aumentar o investimento público- não provocou qualquer reação por parte das expectativas do mercado sobre a evolução esperada do PIB, da inflação e da taxa de juros nos próximos anos (pelo menos a julgar pelos dados disponíveis no sítio do Banco Central na Internet). O mercado, portanto, não se impressionou com os $\mathrm{R} \$ 67$ bilhões de investimentos do governo federal (excluindo estatais) e R \$ 441 bilhões de investimentos das “empresas estatais (federais) e outras fontes" anunciados para o período de 2007 até 2010. O mercado tampouco deu importância às outras dúzias de medidas de "melhoria no ambiente do investimento", "desoneração e aperfeiçoamento tributários" e "fiscais de longo prazo", anunciadas pelo Ministro Mantega (Presidência da Republica, 2007).

O mercado tem lá seus motivos. O lançamento do PAC, afinal, não mexe na essência da política macroeconômica seguida nos últimos quatro anos e - como se isso por si só já não bastasse - a maioria das medidas anunciadas terá que ser negociada (e, provavelmente, modificada) no congresso. Além disso, com exceção da redução do superávit primário e da elevação dos investimentos públicos, os traços “desenvolvimentistas" do programa são tímidos e aparecem misturados a um conjunto de medidas que beiram o senso comum, como a "retomada das negociações sobre a reforma tributária" e a "melhoria da gestão da previdência". Nada, enfim, capaz de assustar os "rentistas" e/ou excitar o setor produtivo. $\mathrm{Ou}$, mais precisamente, o pouco que se poderia fazer pelos últimos sem bater de frente com os interesses dos primeiros na manutenção do regime (explícito) de metas de inflação e (implícito) de metas de superávit primário e redução da dívida líquida do setor público como proporção do PIB. A permissão implícita (dada pela falta de reação) do mercado para a troca de $0,5 \%$ do PIB da meta de superávit primário por $0,5 \%$ do PIB em 
investimentos públicos - a grande medida concreta associada ao PAC, em nossa opinião - é um dado crucial. Aparentemente, o mercado finalmente se convenceu que melhorias na infra-estrutura pública são cruciais, se não para garantir a "retomada do crescimento" (expressão ora em desuso, por motivos óbvios) ao menos para garantir algum crescimento, mesmo que modesto. Esse, aliás, parece ser o objetivo pragmático do PAC: aumentar o nível e a previsibilidade dos investimentos públicos a fim de coordenar as expectativas do setor privado e incentivá-lo a participar do processo de modo complementar. Com isso, seria possível obter melhorias, ainda que modestas e graduais, nas taxas de crescimento do investimento e do PIB sem forçar as expectativas inflacionárias para o alto, de modo a viabilizar a continuação da queda das taxas de juros reais (a despeito do incompreensível e danoso conservadorismo do Banco Central, mesmo quando analisado dentro dos cânones dos modelos de inflation-targeting) e, portanto, da desigualdade de renda no país. Nada mais cauteloso, enfim, como parece concordar o mercado.

Ainda que torçamos pelo sucesso dessa estratégia, parece-nos forçoso reconhecer que nossos dados (admitidamente imperfeitos) parecem indicar que elevações do investimento público não foram, geralmente, acompanhadas de elevações do investimento privado nos últimos 12 anos. Como demonstrado acima, nossas estimativas parecem indicar que a diminuição da carga tributária parece ser um modo mais eficiente de se aumentar a taxa de investimento privado do país.

Naturalmente, nossos resultados não invalidam o esforço do governo, uma vez que os mesmos se baseiam na experiência passada e, se bem implementado, o PAC pode perfeitamente marcar o início de um novo modelo de relacionamento entre os setores público e privado. Além disso, nossos dados não permitem a desagregação do investimento público por tipos de investimento - um ponto central na discussão do PAC. Poder-se-ia conjecturar, por exemplo, que investimentos públicos em infra-estrutura são complementares ao investimento privado, enquanto que investimentos públicos (incluindo estatais) na produção de bens finais (como latas de óleo lubrificante para veículos, por exemplo) são substitutos dos investimentos privados. Nossa base de dados não permite que testemos tais hipóteses, entretanto. Com efeito, o conceito de "formação bruta de capital fixo" - a variável de investimento que utilizamos - é muito amplo, abarcando teoricamente (i) investimentos familiares em residências; (ii) investimentos de empresas e/ou do governo em novas instalações administrativas (e.g. em um novo galpão ou na reforma de um andar de um prédio); (iii) investimentos do governo em infra-estrutura (e.g. de energia e transportes); e, 
finalmente, (iv) investimentos de empresas em novas máquinas e equipamentos. Uma vez que esses investimentos tendem a ser determinados por variáveis bastante diferentes entre si, a tentativa de se estimar "uma função investimento" que explique o agregado dos mesmos é, já de saída, um exercício problemático ${ }^{6}$.

Tampouco o PAC ignora totalmente a importância da desoneração do investimento produtivo e da diminuição da carga tributária. Muitas medidas do plano vão nessa direção, ainda que essas nos pareçam bem mais tímidas e/ou genéricas que as relativas ao aumento do investimento público.

\section{Gráfico 1. Taxa de crescimento do PIB e carga tributária no Brasil}

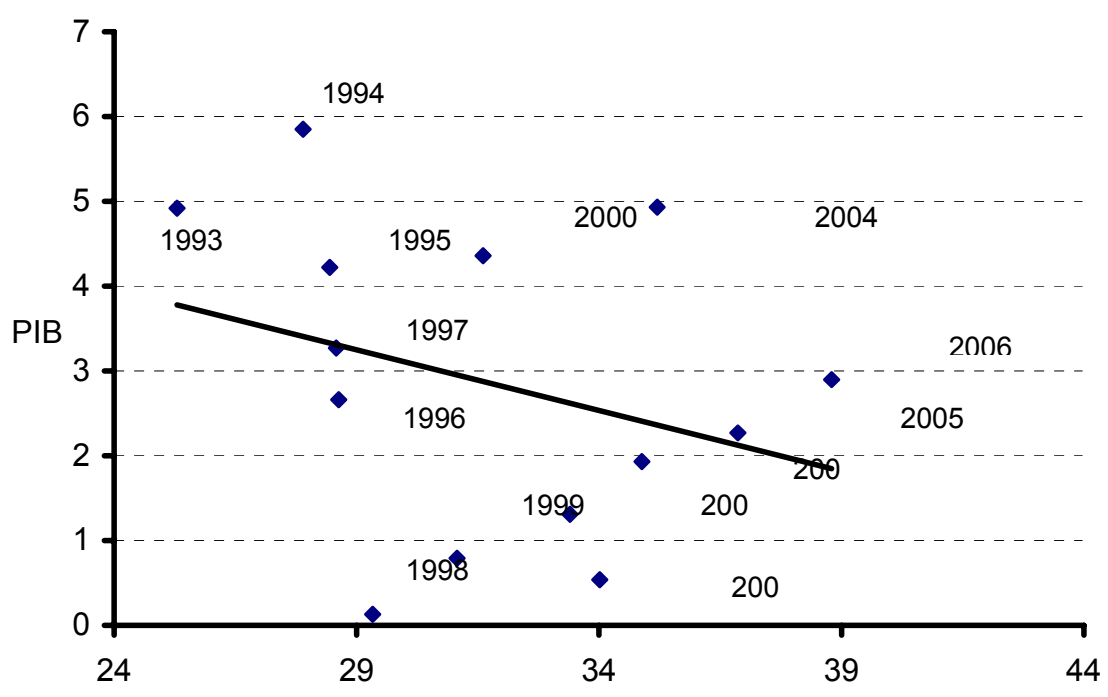

Ainda assim, cabe a indagação sobre se a elevação dos investimentos públicos é mesmo a melhor maneira de elevar a taxa de investimento da economia. Não seria melhor, por exemplo, concentrar esforços na diminuição da carga tributária e na desoneração dos novos investimentos? A resposta a essa pergunta não é fácil, nem - pelo menos ao que nos parece - deve ser respondida por econometristas. A esses, acreditamos, cabe primordialmente alertar a sociedade para os trade-offs existentes entre os vários objetivos das políticas públicas e, quem sabe, palpitar sobre as elasticidades envolvidas. Estudos recentes de Sergei Soares (2006) e Fábio Giambiagi (2006), ambos do IPEA, por exemplo, deixam claro, respectivamente, que os programas de transferência de renda defendidos pelo governo Lula contribuíram decisivamente para a redução da (ainda brutal) desigualdade de renda do Brasil e que as necessidades de financiamento desses programas explicam boa parte da elevação da

\footnotetext{
${ }^{6}$ Mudanças na composição do investimento publico podem perfeitamente explicar, por exemplo, o fato de não termos encontrado uma relação robusta entre essa última variável e o investimento privado.
} 
carga tributária nos últimos anos. Nosso estudo, por sua vez, sublinha que a elevação da carga tributária parece ter tido implicações negativas sobre a taxa de investimento e, portanto, de crescimento (e redução da pobreza absoluta) da economia. Nesse sentido, acreditamos que há um importante trade-off entre crescimento e carga tributária/distribuição de renda no Brasil (ver o sugestivo gráfico 1 acima) que deve ser discutido democraticamente pela sociedade brasileira - de preferência à luz de dados macroeconômicos melhores do que os hoje existentes.

\section{Conclusão}

Em nossa opinião, o PAC deve ser entendido como o esforço desenvolvimentista possível em tempos de consolidação das instituições democráticas e da cidadania brasileiras e, simultaneamente, de "supremacia dos mercados (financeiros)" (Carneiro et al. 2006). Não deve ser difícil, mesmo para o observador mais cético, reconhecer que a compatibilização dos interesses dos credores do estado brasileiro, do capital produtivo do país, e dos cidadãos brasileiros pobres não é tarefa fácil. Também não deve ser difícil reconhecer que, historicamente, (i) resoluções abruptas desse "conflito distributivo" contrárias aos interesses do primeiro grupo têm se mostrado particularmente custosas do ponto de vista da estabilidade macroeconômica; e que (ii) tem sido perfeitamente possível manter taxas elevadas de crescimento econômico sem que os interesses do último grupo sejam contemplados. A tentativa de reduzir gradualmente a dívida pública brasileira (e, portanto, o poder do primeiro grupo) aumentando simultaneamente a participação relativa do último grupo é sem dúvida inédita na história do país e quaisquer análises que negligenciem esse ponto nos parecem como as proverbiais tentativas de encenação de Hamlet sem o personagem principal.

Naturalmente, nada do que foi exposto acima nos autoriza a concluir que os interesses dos brasileiros mais pobres não estariam mais bem servidos com uma menor oferta de serviços públicos no presente e, portanto, uma maior taxa de crescimento e serviços públicos no futuro. Mas não custa lembrar que nada autoriza os defensores do consenso "macroeconômico" referido acima a afirmar o contrário. Ou alguém - principalmente alguém que nunca padeceu dos males que assolam a vida dos cidadãos mais pobres de nosso país está disposto a arriscar as características das preferências intertemporais (sob incerteza) médias das várias gerações de brasileiros pobres? 